\title{
Subjective Experience of Past - Life Regression
}

\author{
${ }^{1}$ Hargun Ahluwalia, ${ }^{2}$ Jini K. Gopinath \\ ${ }^{I}$ (Mphil Trainee, Dept. of Clinical Psychology, NIMHANS, Bangalore \\ ${ }^{2}$ (Assistant Professor, Dept. of Psychology, Christ University, Banglore)
}

\begin{abstract}
The aim of this study was to examine the subjective experience of past - life regression (PLR). 15 graduate students underwent PLR facilitated by a trained professional for this purpose. Using Interpretative Phenomenological Analysis (IPA), the data collected from the interviews with these individuals was analyzed. The participants were able to relate their experiences under trace with their present life scenarios and could find meaning in their experiences. Most participants reported positive effects of the experience and this may have implications for further research and therapy with non-clinical populations.
\end{abstract}

Keywords: Past - life regression (PLR), Hypnotic trance, Interpretative phenomenological analysis (IPA), Meaning, Experience.

\section{Subjective Experience of Past Life Regression}

The phenomenon of experiencing one's past life through hypnotic procedures is a much debated and inadequately studied arena in hypnosis research. Research however, has focused on the abilities persons develop when they have undergone hypnotic trance. It seems that persons who have been hypnotized can experience sensations that have been called psychic. For example a hypnotized person may report perceiving sensations experienced by another person. This is called 'community of sensation', and is considered today as a form of telepathy. Hypnosis also seems to be a favorable condition for many forms of extra- sensory perceptions (ESP) and those who are hypnotized perform better on clairvoyance, telepathy and precognition than others. Varvoglis (n.d.) explains that under hypnotic trance the person is completely relaxed and thus not distracted by internal and external noise as much as a consciously alert person is. Hence attention can be directed fully to subtle psychic sensations. A hypnotized person's thinking as well as physiological conditions favors good ESP performance. Fear and hesitation are removed and confidence can be heightened in this suggestible state.

Taking from this it may also be said that under hypnosis a person can perceive and experience what has lain in his unconscious mind for decades or generations. The idea of past life recall under hypnosis would need to endorse the principle of reincarnation or of a Jungian collective unconscious (Jung, n.d.). If we were to adhere to these principles each account of a past - life would indeed refer to a past existence and its veracity then would need to be validated for the account to hold any value.

However, in the present study, what is important is the experience each participant went through under trance and if there was any benefit or harm from the experience. The veracity or validation of the experience is of little consequence in this regard and thus, we will refrain from indulging metaphysical debates around these concepts.

There is abundant literature available on hypnosis and its applied effects in several areas including age regression. In the field of past - life, cases have been documented across the globe of spontaneous recall of past lives. While the recall of a past - life through the hypnotic process of past - life regression has been theoretically explored, actual cases in this area are limited. The cases that have been documented are those in which phobias, anxieties and/or fears are present or there are other clinical manifestations.

This study aims at understanding the experience of past - life regression on a non- clinical sample of persons. This will provide research results for a rather neglected area of study and will help understand how lay persons make sense of the phenomenon of past - life. It will also provide insight into the possible benefits or ill- effects of the process.

Past - life Regression (PLR) is a technique that uses hypnosis to uncover memories and events of a previous life. It is an umbrella term that includes a wide range of processes and experiences. One of the first PLR cases to be reported and perhaps the best known is that of Bridey Murphy. In this case an American woman recalled on several occasions under hypnotic trance, details of a past - life in Ireland over 150 years prior to her current life. Under hypnosis induced by Bernstein (1956), the American woman Ruth Mills Simmons gave Bridey's date of birth, where she was born, her parent's names, whom she married, where she settled down after her marriage and how she died. Investigations into the case revealed that most of the details were modifications of information from Simmons' childhood and could not be correlated to geographical or biographical information in Ireland. Gravitz (2002) discusses the possibility that the client's expectancies, prior hypnotic 
experience with the hypnotist and suggestibility created a kind of unconscious transferential relationship. The client's crytoamnesia, the author believes, was reinforced by hypnosis.

Of the scarce literature available on the experience of PLR, the following section outlines some research. Knight (1995) discusses the description of the experience of PLR as given by Grof in 1988. This experience has been understood as being dramatic and intensely emotional. The subjects in PLR retain their identity but the context changes. Van Beekum and Lammers (1990 as cited in Knight,1995) document certain experiences that they call the 'past - life state', which they define as

A specific, ego syntonic, altered state of consciousness in which the person experiences a coherent system of visual, auditory, kinesthetic, and/or olfactory sensations within a clear historical context. This context is consistent in time and place, it seems to date from a single historical period before the present life of the individual, and its content usually refers to traumatic experiences.

Knight also discusses Moody and Perry's (1990) characterization of past - life experiences- usually visual, having an uncanny feeling of familiarity and often mirroring present issues in the subject's life.

Woolger (2002) in his work describes the bodily involvement in PLR. In many sessions the client doesn't just sit or lie passively with his or her eyes closed. Instead, Woolger reported dramatic convulsions, contortions, heavings and thrashings. He found that in the trance state, the subjects felt vivid bodily sensations, often distinct in one part from the other, i.e. "My head may think this, my heart may feel that, my guts may feel something else and so on. Every part of the body has something to say or express".

In a research paper by Eric J. Christopher (2000) titled 'Exploring the Effectiveness of Past- Life Therapy', the author mentions a study by James (1993), in which 104 subjects were hypnotized and 81 of them reported vivid past-life images. James noted that the depth of each hypnotic state had a significant impact on whether or not the person reported past-life scenarios, as well as the amount of detail given regarding the pastlife image. He also found that religious beliefs, religious involvement, education and expectation about recalling past lives had no significant effect on whether or not the subject produced past-life images.

\subsubsection{Validity of past - life recall}

Critics have continually raised doubts about the validity of past - life recall (E.g. Gravitz, 2002).The cases that have been reported have been glorified and those with inaccuracies have perhaps never made it to print. In 4 studies by Spanos et al (1991), it was found that past- life reporters frequently gave inaccurate historical details and made other historical errors. It was also found that children who were highly imaginative tended to experience intense past- life experiences. Results also indicated that past - life reports were a product of imagination, preconception and suggestions.

Subjects who were told before being up under hypnosis that they had probably undergone child abuse in a previous life, recalled higher levels of abuse than those who were not given any such information. Integration of pre- hypnotic suggestion into the experience during hypnosis was especially integrated when the suggestions were negatively toned. These studies point to the idea that these memories of past- life may only be imaginary and may not account for real experiences. In context of clinical cases that undergo past - life regression hypnotherapy, it is important to understand that whether or not their experience is authentic, it is surely a manifestation of the deep recesses of their mind. In these cases therapeutic benefit from such memories is more important than the validity of these memories.

\subsubsection{PLR and therapeutic effects}

Marquez (1999) found that remembering pre and prenatal experiences can significantly benefit one's life. The author conducted a study on 7 adults, in which some of the benefits experienced were changes in vision, healing of arthritis and relief from asthma. The subjects felt empowered and felt a greater control over their life.

Woolger (2002) throws light on how regression to past experiences, in the present or previous lives can have significant therapeutic benefit. He discusses the case of a woman who suffered from post traumatic stress disorder symptoms (PTSD) symptoms for 20 years since a car accident where she went through a NDE during subsequent surgery to save her life. When age regression was done on her to relive the incident, she described in detail watching her body being pulled from the wreckage, being taken to the hospital and then into surgery, ascending to a higher realm and meeting deceased members of her family who shone with very bright light. When she returned to her physical body, she found her pain coming back. Before this session of regression, she had not remembered these details and the session profoundly altered her outlook towards death and dying.

Zahi (2009) discusses 3 cases of therapeutic benefit from hypnotherapy. The first of these cases was that of a woman who complained of high levels of anxiety, pain and memory problems. Through hypnosis she regressed to the age of one year and found that he father was being hostile towards her and despite calls for her mother, she did not come to her rescue. At this she felt hatred for her parents and also realized that as a mother herself she did not protect her own daughter from her ex- husband. At this she felt very guilty. For next few sessions she wanted her memory problems to be worked upon. She underwent past - life regression therapy. 
Subjective Experience of Past - Life Regression

First she found herself in Egypt where her baby was killed and buried with the Pharaoh. She felt extremely guilty that she could not save her child. She also realized that her baby's soul was at peace and this brought her relief. In another PLR session she found herself as a mother during the holocaust that died but saved her son. This memory surprised her and she said that she had never saved anyone before. She said that this memory filled in the gaps in her memory that she was struggling with and she did not have memory problems again.

The second such case in which symptoms were removed completely through hypnotic suggestion was that of a Jew, who strongly believed in the idea of the soul leaving the body and accepted it without question. Interestingly, Zahi proposes that benefit from therapy can also be felt by non- believers or those whose beliefs oppose that involving non- material elements such as the soul.

Woolger regressed a social worker, Juan who had come to the therapist with the problem of social phobia. It was found that he was hung because he had stolen bread in medieval Europe. The therapist in the course of the session put a towel around his neck as suggestive of the hangman's rope. The therapist also directs Juan's attention onto all those who did not think he was wrong. In the end, Juan wanted the weight of the towel lifted and did so himself, symbolically freeing himself from the guilt of the steal and the pressure of the critical eyes that had blamed him. This approach has been understood as hypnodrama, which is essentially psychodrama under hypnosis. In hypnodrama, the person's defenses are significantly lowered and thus he/ she does not experience embarrassment or resistance about acting out in the therapy session. Also access to unconscious conflicts and emotions is abundant and therefore the process of ventilation is very rich.

Woolger describes the case of a woman called Marion who suffered from anxiety attacks and depression especially when someone left her home or when someone was late in arriving home. She always dreaded that something terrible had happened to them. Through PLR, Woolger found that in a previous life, she was an African boy who had left the village to hunt only to return to find his mother and siblings slaughtered. He was also killed by the soldier on his arrival. His last thoughts were that he should have not left them alone. After death, Marion claimed that the boy stayed in the house for several days, after which he felt that he was leaving the village and floating above it. After death the boy reunited with his parents, who tell him that there is nothing that he could have done to save them. Thus it is evident that the reason for anxiety in the present life stemmed from past trauma. The outlet that the regression served might have been cathartic in releasing the sense of anguish and guilt that has been carried to this life.

Woolger (2002) also reports the case of Heather, who came for therapy as she suffered from ulcerative colitis since early adolescence. When no significant conflict emerged through age regression, PLR was carried out. In the session she regressed to Holland during World War II at the time of the Nazi invasion. She found herself as an eight- year old girl in a Jewish family who while fleeing from an explosion was captured and subsequently killed. She described her bodily sensations as she awaited her turn to be in front of the machine gun fire and felt her stomach knotted in terror. When she is shot, she fell on a pile of dying bodies and eventually died of blood loss and suffocation. For all this time, she had not been able to express the shock and trauma of having lost her parents, seeing mass slaughter and facing her own premature death, which may have resulted in bodily manifestations. In the session, she was allowed to release her anguish through cathartic sobbing, screaming, violent convulsions and dry vomiting. After the session her stomach problem improved significantly.

Thus several cases point towards the likelihood of current pathologies in the present life arising from psychic residues of previous births.

To recall the phantom pain of having a sword in one's side, or of having one's flesh burned, or one's head cut off puts us in touch with deep traumatic residues that have actually persisted across lifetimes. Such physical memories, that have nothing to account for them in the current life, turn out to be embedded in what is literally the subtle energy field that surrounds and penetrates the physical body.... These old traumas, inherited though the subtle field, are consistently found in our work to re-imprint in the current body as rashes, birth marks weaknesses in certain limbs, organic problems such as a weak bladder, a weak heart and so on.(Woolger)

In the field of PLR for non- pathological individuals, Woods and Baruss (2004) conducted a study with 24 students. Each of them participated in a single guided imagery session in which they were given either a pastlife or open suggestion. Participants who were given the past-life suggestion had better scores on measures of psychological well-being than those given the open suggestion.

However, the research on increased well- being and/or cathartic release as possible benefits of PLR on those who do not suffer from any somatic or psychological problem has not been explored abundantly. There is a need to explore the benefits of this therapy for the non- pathological population so as to extend psychotherapy to this majority population to enhance the quality of life.

\section{Methodology}

The aim of the research was to study the subjective experience of past- life regression. Its objective was to find if any, therapeutic benefit through the process of PLR for the non - clinical population. The study is an ontological one which accepts multiple realities and subjective uniqueness. Thus the mode of enquiry 
adopted is phenomenological in which no claim is made with regard to the quality of the experience but rather it is the presence of the experiencer that counts (Cresswell, 2003). Participants had vastly varying phenomenal experiences which were real and lived for them and for the purpose of the study their account of the experience is of utmost importance.

In this study an attempt has been made on the part of the researchers to 'bracket' and 'suspend' preconceived notions and understand the experience of PLR as it is experienced by the participant. At the same time, the researchers also adopt a hermeneutic stance to the study and believes that their life experiences have shaped her perception and inferences of the participants experience in the research. This interpretative stance helps the researcher identify the active role they have played in the process of interviewing, transcription, analysis and discussion.

The hermeneutic stance is also extended to the phenomenological participants because they too actively interpret and infer about and from their experience. Thus the qualitative research approach adopted was that of interpretative phenomenological analysis (IPA).

\section{Sample}

The sample was selected through purposive sampling, which is most appropriate for the research question. The research sought the experiences of persons who had undergone past- life regression trance and thus any other mode of sampling would not have sufficed. A fairly homogenous sample of psychology students attending a hypnosis workshop were selected as they had undergone PLR induction in the course of the workshop. Such a purposive homogenous sampling has been recommended by Smith, Flowers and Larkin (2009). The authors also discuss that the primary concern in IPA research is that of quality rather than quantity and that sample size is not of much consequence. The understanding is that each human experience is complex and constitutes for rich data and therefore, a small number of cases with a concentrated focus can make for a good research. They suggest a sample size of three to six as being reasonable. They treat $n=3$ as the default size for an undergraduate or Masters- level IPA study. For the study at hand, the sample size chosen was 15 of which 14 are women. This number was chosen amongst 80 participants, by selecting those persons that reported having had a recallable and recognizable experience. The sample comprised graduate students, between 21 to 24 years of age and thus an average to above average intellectual functioning was assumed of the sample. The sample was selected from a non- clinical population and individuals who did not have any psychiatric disorder and/or psychological disease. Also the participants did not have a history of regular or frequent intake of any drugs. The study was conducted on a non- clinical sample so as to understand their experience and beliefs about PLR.

\section{Procedure}

The PLR trance was induced by the trainer of the hypnotic workshop, Dr. Nitin Shukla, on 80 individuals studying in Christ University in graduate and post- graduate psychology departments. The process of induction and sustenance of trance was observed and observational data was recorded. After the persons were brought out of the hypnotic state, they were asked by the researcher about their experience and if they could recall adequately what they had seen or heard, a request for participation in the study was made. An informed consent form was signed informing the participants about the nature of the research and assuring them that their experiences will be kept confidential, to the best of the researcher's capability.

For the collection of data, semi- structured interviews were conducted. In the process of interviewing, the key areas inquired about were:

- Complete account of experience

- Emotions and sensations experienced

- Beliefs and change in beliefs after experience

- Discussion of the message in the past- life

All the interviews were tape-recorded with the participants' consent, and afterwards transcribed. The interviews were conducted within a few hours of the trance induction, in the same place as the induction. Each interview was approximately 15 minutes in duration.

\section{Data analysis}

The analysis of data was carried out through IPA. Each transcript was read several times to be familiar with the content. Each participant's idiographic experience was subjected to detailed analysis. Recurrent themes were coded within and between transcripts. A list of themes was produced and interconnections and their possible meanings were analyzed.

Throughout the process transparency and knowledge was maintained on the part of the researcher in providing to the subjective experience of participants, elements of her own interpretation. 


\section{Discussion}

The objective of the study was to understand the subjective experience of past - life regression and identify if any, therapeutic benefit for a non- clinical sample. The 15 participants had very different experiences and had very different viewpoints about them. Broadly however it was evident that the experiences were rich in sensations and feelings. The participants felt their experiences and felt them as their own. Each story was experienced with immense personal connection. The participants truly lived their experience and did not merely watch it. They felt the fear and the happiness, the feelings of others around them and their feelings about themselves. Their intuitive sense also seemed very active as they obtained information about their nature and environment, without any sensory stimulation. Despite their involvement, it appears that the participants were not completely immersed in the there - and - then. There vague and subtle awareness of the here - and - now allowed them to take up a witness role in their experience as well. They were able to make inferences and identify discrepancies between the suggestions and the past - life story. They were able to direct themselves through the story and make sense of their puzzlement and surprise.

The interpretative role which each participant pursued after the PLR session, during the interview was insightful not only for the sake of this research, but also for them. Many participants were able to relate their PLR stories with their present lives. Some identified patterns of behavior in the present life that they felt may have arisen due to the events of their past - life. One participant found that she had been resisting religion in her present life and could now see that she needed to know it before running away from it. Grief was (re)lived and cathartized. Contentment and happiness in the PLR experience left the participants feeling that their past - life was meaningful and that this must have some value in their present life too. While very few persons received a message in their experience, those who did found it appropriate and could relate it to their current situation. There was a lot of skepticism and uncertainty about whether or not the experience was actually of a previous existence. Many believed that it was a dream or their imagination. On the other hand many also thought that there was a high chance that their experience was of a past - life.

The realization that one may have lived before and thus, may be born again after their death in this life, is an overwhelming idea at first. The resistance experienced to it to was evident in all the participants. Several theories apart from that of reincarnation have been posited to explain past - life recall. From the psychodynamic approach, the experience can be understood as the release of unconscious information into the conscious mind. Hypnosis it is believed lowers the defenses that operate to repress the conflicting and disturbing unconscious information. Thus it becomes more easily accessible to the conscious mind. It is believed however, that this information is necessarily of the "shadow" or disturbing kind, which was not the case for most of the subjects who had a pleasant or a neutral experience. Psychoanalysis stands divided on their stance on reincarnation. While most psychoanalysts did not propagate the phenomenon, Jung wrote extensively about the traces of ancestral images and complexes than constitute the unconscious mind. This 'collective unconscious' could thus, be the source of past - life memories (Cunningham, 2009).

Cryptoamnesia has also been considered as being the source of recall of past - life memories. It is held that subjects recall under trance information to which they were exposed but subsequently forgot. The information may be given to them in their childhood, through photographs or through other sources but they forget it and it emerges under hypnosis in altered form. The case of Bridey Murphy, the first documented cases of PLR has been dismissed as being a case of cryptoamnesia as the subject hardly gave any verifiable details and incorporated various forgotten details of her childhood into her PLR memories. For example the subject had a brother who died when she was five years old. The deceased personality Bridey too, the subject claimed had a brother who had died when she was four years old. Many connections were found between her present and past - life (Gravitz, 2002).

In the present study too, there have emerged many connections between the participants' experience of PLR and their present lives. None of these connections are specific, but rather are related to the subject's personality characteristics and choices. Participant 2 for example felt that she handled goodbyes badly in this life because her husband and child died suddenly and unexpectedly in her past - life experience. She felt lonely and was grief stricken and this may have translated into her present personality fearing being left alone. Participants did not mention specific things that could have been forgotten details from this life. However, it must also be mentioned here that the hypnotic trance was short lived (for about thirty minutes) and if further exploration had been allowed, the nature of information that may have come to the fore cannot be gauged. Also efforts to verify the accounts of the participants exceed the scope of the present study and have not been undertaken.

Gravitz (2002), discusses the possibility that the client's expectancies, prior hypnotic experience with the hypnotist and suggestibility creates a kind of unconscious transferential relationship. The client's crytoamnesia, the author believes, is reinforced by hypnosis.

Critiques have also claimed that apparent past - life memories are revealed for popularity, fame, money or any other gain (Pasricha, 1990). This form of fraud may be safely ruled out in the present study. The participation was completely voluntary and no reward or incentive was offered. Each participant was ensured 
that the interview material would remain strictly confidential and would be used for research purposes only. Thus, there was no doubt in the participants' minds that no publicity for their stories could be achieved through this research.

Another and in this case valid critique of PLR is that the memories are often a result of 'role playing'. The participants may be keen on following the suggestions given by the hypnotist and may be driven to please him. Thus the experience would then be shaped by the expectations of the hypnotist and vivid, dramatized recall of memories would be seen.

The attributes of social desirability certainly cannot be imposed on the group of graduate students who attended the workshop. If that was the case many more out of the 80 participants would have had vivid memories to recall. While it is evident amongst the participants' accounts that their experiences were indeed shaped by suggestion to some extent, many participants also experienced aspects that deviated considerably from the suggestions given. Also, the recall for most participants was far from vivid. They had blurry, confusing experiences and were struck by the unexpected nature of the experiences. Most participants reported that they were surprised at what they felt and saw and were not actively constructing but rather watching an experience spontaneously unfold. However, it cannot be negated that some participants' experience may have been shaped by hypnotist's suggestions and expectations largely and that they may have in fact been 'role playing'.

Several other factors may influence the experience including the participants' suggestibility and resistances, as well as their beliefs.

The role of belief systems seems to be important in providing the uniqueness in to each participant's experience. Woerlee (2009) pointed out that while there exist certain universal features in reports of Near Death Experinces across the globe, persons from different cultures perceive different divine figures corresponding with their religious beliefs. In the present study too, participants could relate their experiences to their present lives and their beliefs. This facilitated sense making and made each experience personally relevant and unique from the rest. Participant 9 and 15 for example, had several religious elements to their experience. They saw themselves in the experience as being of the same religion as they are in their current life.

While many hypotheses regarding the validity of the experience can be posited, the experience in itself cannot be negated. It was this experience that the study aimed to explore and it is not within the scope or the aim of the research to question or negate the experience. The experience was personal and important to each of the participants and this must be respected.

The meaning- making process that the participants engaged in after the experience was interesting. Most of the participants were able to find some insight or learning from the experience, either about their personality or about life in general. The experience also provided cathartic relief to some and was relaxing and mood- lifting for others. No negative effects were reported of the hypnotic trance. The rationale behind the exploration of a previous existence is to be able to see oneself as having existed in a different from and hence appreciate and know oneself in this life better. Many participants reported that they could cherish what they have in this present present life now that they had seen what kind of life they had had previously. Also, when past lives are delved into, one realizes the bond that is shared over millennia with all humanity. This may increase one's tolerance towards people around them and change their outlook towards life in general.

These results have very important implications for hypnotherapy and hypnosis research.

While the present study has not provided any evidence supporting tangible therapeutic benefits of PLR, it has suggested that PLR may produce positive results with non- clinical populations. It may help identify and interpret personality and pattern characteristics and further therapy might engage in the process of modifying these. Thus therapy with families, couples or other non- clinical cases may be undertaken with PLR so as to understand their unconscious processes.

This study has been limited in several ways: firstly, the sample size was too small to reach at generalizable aspects of the PLR experience. Also, each participant underwent the PLR only once and thus their experiences were not very detailed. Also the participants were not questioned under trance as a group induction was carried out. The interview was answered retrospectively and thus some details may have been missed out. Also the participants underwent the process through only one form of hypnotic induction and if the indirect hypnotic paradigm was applied, the experience may have been completely different. Also if different therapists had carried out the induction, it is likely that the experience would have been different.

Participant characteristics like their belief systems, their expectations of the session and their prior knowledge of past - life regression are all variables which may have affected the findings of the study but were not controlled. The participants were pursuing their studies in psychology, knowledge of which may have led them to experience the trance differently as well.

Research undertaken in the future must look into these aspects. A larger sample from a different population may be undertaken for future research so as to arrive at generalizable findings. Clinical research using the pre and post experimental design could also be pursued to as to examine the therapeutic benefits of PLR therapy. A comparative study comparing different paradigms of PLR (direct vs. indirect suggestions) and 
different therapists may be undertaken to arrive at therapist qualities most suited for benefit from therapy as well to standardize PLR induction protocols.

Thus, there is immense scope for research and practice in this area of hypnotherapy, not only for clinical but non- clinical populations as well.

\section{References}

[1] Cunningham, P. F. (2009). An Experimental Investigation of Past - Life Experiences. (Unpublished researchproposal).Retrievedfromhttp://www.rivier.edu/faculty/pcunningham/web/myweb/An_Experimental_Study_of_PastLife_Experiences_2009.pdf

[2] Christopher, E.J.(2000). Exploring The Effectiveness Of Past- Life Therapy. (Research Paper). Retrieved from http://www.uwstout.edu/static/lib/thesis/2000/2000christophere.pdf

[3] Creswell, J.W. (2003). Philosophical, Paradigm, and Interpretative Frameworks. In Qualitative Inquiry and Research Design: Choosing Among Five Approaches. Sage Publication Gravitz, M.A. (2002). The Search for Bridey Murphy: Implications for Modern Hypnosis. American Journal of Clinical Hypnosis, vol. 45, no. 1, pp 3- 10, American Society of Clinical Hypnosis. Retrieved from http://www.asch.net/portals/0/journallibrary/articles/ajch-45/gravitz.pdf

[4] Jung, C. G. (1940).'The Concept of the Collective Unconscious.' Retrieved from http://www.uky.edu/ aubel2/eng104/dreams/pdf/jung-cu.pdf

[5] Knight, Z. (1995). The healing power of the unconscious: how can we understand past - life experiences in psychotherapy?South African Journal of Psychology, Vol. 25, Issue 3 http://web.ebscohost.com/ehost/detail?vid=4\&hid=119\&sid=a186daa2-6c5b-490fae67-9201f25ec2f2\%40sessionmgr114\&bdata=JnNpdGU9ZWhvc3QtbG12ZQ\%3d\%3d\#db=pbh\&AN=33216803

[6] Marquez, A. (1999). Healing Through the Remembrance of the Pre- and Perinatal: A PhenomenologicalInvestigation.Retrievedfromhttp://static.ning.com/holotropicbreathwork/research/marquez1999.pdf

[7] Pasricha, S.K. (1990). Claims of Reincarnation; An Empirical Study of Cases in India. Harman Publishing House, New Delhi.

[8] Spanos, N.P., Menary, E., Gabora, N.J., Dubreuil, S.C. and Dewhirst, B. (1991). Secondary Identity Enactments During Hypnotic Past- Life Regression: A Sociocognitive Perspective. Journal of Personality and Social Psychology, Vol. 61, No. 2, pp 308- 320, American Psychological Association, Inc. Retrieved from http://construct.haifa.ac.il/ ofram/spanos et al.pdf

[9] Smith, J.A. (2010). Interpretative Phenomenological Analysis.Existential Analysis, Vol. $21, \quad$ No. 2. SocietyforExistentialAnalysis.Retrievedfromhttp://web.ebscohost.com/ehost/pdfviewer/pdfviewer?hid=10\&sid=7ec573ad-e13f40c3-a5b3-2126cf6fa54a\%40sessionmgr14\&vid=1

[10] Smith, J.A. and Osborn, M. (2003).Interpretative Phenomenological Analysis. J.A. Smith (ed.), Qualitative Psychology: A Practical Guide to Research Methods, Sage Publications

[11] Smith, J.A., Flowers, P. and Larkin, M. (2009). Interpretative Phenomenological Analysis: Theory, Method and Research. Sage Publications.

[12] Varvoglis, M. (n.d.). Hypnosis and Psi. Retrieved http://www.parapsych.org/hypnosis and psi.htm

[13] Woerlee, G.M. (2009). The Near- Death Experience: Unanswered Questions. Retrieved from http://www.infidels.org/library/modern/gerald_woerlee/NDE-questions.html

[14] Woods, K. and Baruss, I. (2004).Experimental Test of Possible Psychological Benefits of Past-Life Regression. Journal of Scientific Exploration, Vol. 18, No. 4, pp. 597-608. Society for Scientific Exploration. Retrieved from http://www.scientificexploration.org/journal/jse 184 woods.pdf

[15] Woolger, R. J. (2002). Past - life Therapy, Trauma Release and the Body. T. Staunton (Ed.) Retrieved from http://www.childpastlives.org/library_articles/woolger_PLTherapy.htm

[16] Woolger,R. J. (n.d.). Eternal Return. Retrieved from http://www.rogerwoolger.com/pages/bardos.html

[17] Zahi, A. (2009). Spiritual- Transpersonal Hypnosis.Contemporary Hypnosis, Vol. 26, No. 4, pp 263268,WileyInterScience.Retrievedfromhttp://web.ebscohost.com/ehost/pdfviewer/pdfviewer?hid=22\&sid=06f32b0c-6136-4b969867-6a36fbe $85 \mathrm{c} 44 \% 40$ sessionmgr 12 \&vid=1 